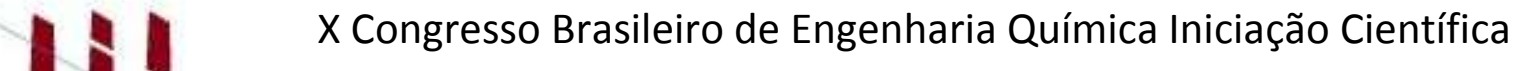 \\ "Influência da pesquisa em Engenharia Química no desenvolvimento tecnológico e industrial brasileiro" \\ Universidade Federal Rural do Rio de Janeiro Universidade Severino Sombra Vassouras - RJ-Brasil
}

\section{SECAGEM DA CASCA DA MEXIRICA POR IRRADIAÇÃO INFRAVERMELHA E COMPARAÇÃO DOS COMPOSTOS BIOATIVOS DESTA IN NATURA E APÓS A SECAGEM}

\author{
GARDUSI $^{1}$, F.; MENDES ${ }^{1}$, L. G.; NOGUEIRA ${ }^{1}$, G. D. R; SILVA ${ }^{2}$, D. I. S.; \\ BARROZO ${ }^{3}$, M. A. S. \\ ${ }^{1}$ Aluno(a) da FEQUI/UFU $\quad{ }^{2}$ Doutorando da FEQUI/UFU $\quad{ }^{3}$ Professor da FEQUI/UFU \\ Faculdade de Engenharia Química - Universidade Federal de Uberlândia \\ Endereço-UFRRJ, Av. João Naves de Ávila, 2121, Bloco 1K, Campus Santa Mônica, Uberlândia - \\ $M G, C E P$ 38408-100, \\ email:masbarrozo@ufu.br
}

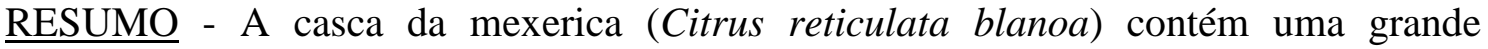
quantidade de compostos bioativos, em especial quando comparada com o suco da mesma, fenômeno muito comum entre as frutas. Devido a sua grande aceitabilidade no mercado e seus elevados teores de vitaminas, minerais e fibras, o presente trabalho procurou analisar a variação dos teores de ácido ascórbico, ácido cítrico, fenólicos totais e flavonoides totais na casca da mexerica in natura e quando submetida à secagem por irradiação infravermelha. Esse processo visa reduzir o volume e seu peso do material, o que facilita seu transporte, reduz os gastos e viabiliza o armazenamento por maiores períodos sem que ele seja deteriorado ou afetado pela ação de micro-organismos. Os testes de secagem foram realizados nas temperaturas: 60, 70, 80 e $90{ }^{\circ} \mathrm{C}$. Pôde-se concluir que o modelo de Overhults é o que melhor descreve a cinética de secagem, apresentando um coeficiente de determinação médio de 0,9993 e a temperatura é uma variável importante para o tempo de secagem. O teor de ácido ascórbico elevou-se com o aumento da temperatura de operação. Excetuando o conteúdo de flavonoides totais, para a temperatura de $90^{\circ} \mathrm{C}$ todos os compostos apresentaram as maiores médias.
\end{abstract}

Palavras chave: resíduos, antioxidantes, cinética de secagem

\section{INTRODUÇÃO}

Com bastante aceitação no mercado de frutas in natura, a mexerica pokan (Citrus reticulata blanco) é a mais cultivada no Brasil (Silva et. al., 2012). A mexerica é rica em vitaminas B1 e B2, as quais auxiliam na prevenção de doenças dos nervos, olhos, pele, cabelos, fígado e boca. Ainda contém grande quantidade de fibras e sais minerais (CEASAES, 2013).

Entretanto, com o consumo in natura e, principalmente, o processamento da fruta há a geração de resíduos, subprodutos provenientes do esmagamento dos frutos para a extração do suco. Muitas vezes estes resíduos não são descartados adequadamente e geram inconvenientes para a indústria e a população 
em geral. Visto isto, é essencial para o setor industrial agregar valor econômico, tecnológico e científico a estes resíduos. Uma possível solução seria a incorporação de farinhas de resíduos desidratados a novos alimentos, auxiliando assim também no combate a desnutrição (Abud e Narin, 2009).

A secagem auxilia na redução de volume e conservação microbiológica. Especificamente, a secagem por infravermelho, método que conta com o aquecimento por irradiação dentro do comprimento de onda de 0,75 até $100 \mu \mathrm{m}$, ainda apresenta a vantagem de utilizar um equipamento simples, de fácil manuseio e gasto energético, significativamente, menor que métodos convencionais de secagem (Sandu, 1986).

Uma alimentação rica em frutas e hortaliças se mostrou eficiente na redução de doenças crônicas (Melo et. al., 2008). Isso se deve ao fato de estes alimentos serem ricos em compostos antioxidades, os quais têm capacidade de neutralizar radicais livres (RiceEvans et. al, 1996; Sousa et. al., 2007).

O excesso de radicais livres é capaz de causar alterações no DNA, envelhecimento precoce, doenças cardiovasculares, degenerativas e neurológicas. $\mathrm{O}$ combate a este excesso é realizado pelos compostos antioxidantes, com destaque para os fenólicos e flavonoides totais, oriundos de produtos naturais (Souza de Sá et. al., 2012).

A acidez é um importante parâmetro na avaliação da conservação de produtos alimentícios. Os ácidos orgânicos presentes influenciam na cor, textura e odores dos alimentos. Além de controlar o crescimento do número de micro-organismos (Souza et. al., 2010). O ácido orgânico 2-hidroxi-1,2,3propanotricarboxílico, comumente conhecido como ácido cítrico é o ácido mais representado na acidez total titulável.

O ácido ascórbico é um componente da vitamina $\mathrm{C}$ e se degrada facilmente, sendo estável apenas em meio ácido, com ausência de luz, calor e oxigênio. Ele age como um potente antioxidante inativando radicais livres e aumentando a resistência imunológica. Além de prevenir doenças como o escorbuto (Odin, 1997). A Agência Nacional de Vigilância
Sanitária (Anvisa, 2011) recomenda a ingestão diária de $45 \mathrm{mg}$ de vitamina $\mathrm{C}$ para um adulto.

Sendo assim, este trabalho teve como objetivo avaliar a cinética de secagem da casca da mexerica pokan em função da temperatura de operação e a influência desta nos teores de compostos bioativos.

\section{MATERIAIS E MÉTODOS}

\section{Materiais}

As mexericas da qualidade pokan utilizadas neste trabalho foram obtidas em um mercado da cidade de Uberlândia-MG. Logo após, as cascas foram separadas da polpa e trituradas. $\mathrm{O}$ material foi armazenado congelado em sacos individuais de peso aproximado de $200 \mathrm{~g}$ e embrulhado em papel alumínio até o momento da realização dos experimentos, como mostrado na Figura 1.

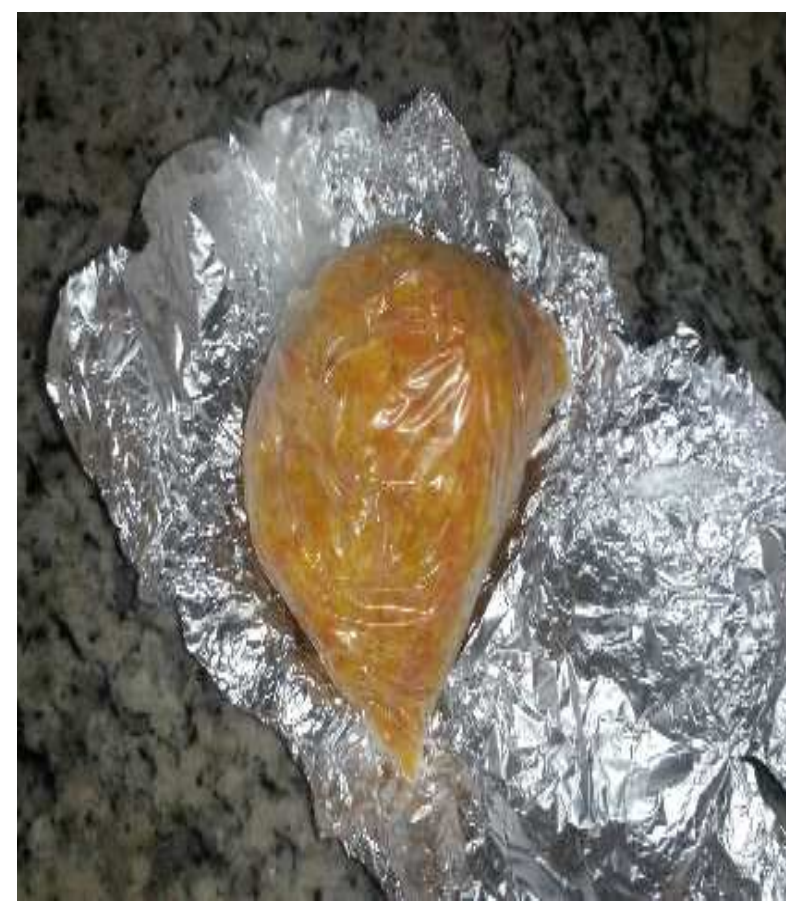

Figura 1 - Saco individuais de casca de mexerica triturada e congelada.

\section{Equipamento e condições de secagem}

O estudo da secagem da casca da mexerica pokan foi feito em um determinador de umidade infravermelho. A Figura 2 apresenta o aparato utilizado.

A variável independente estudada foi a temperatura $\left(60,70,80\right.$ e $\left.90^{\circ} \mathrm{C}\right)$ e o 
experimento realizado até a secagem completa do material.

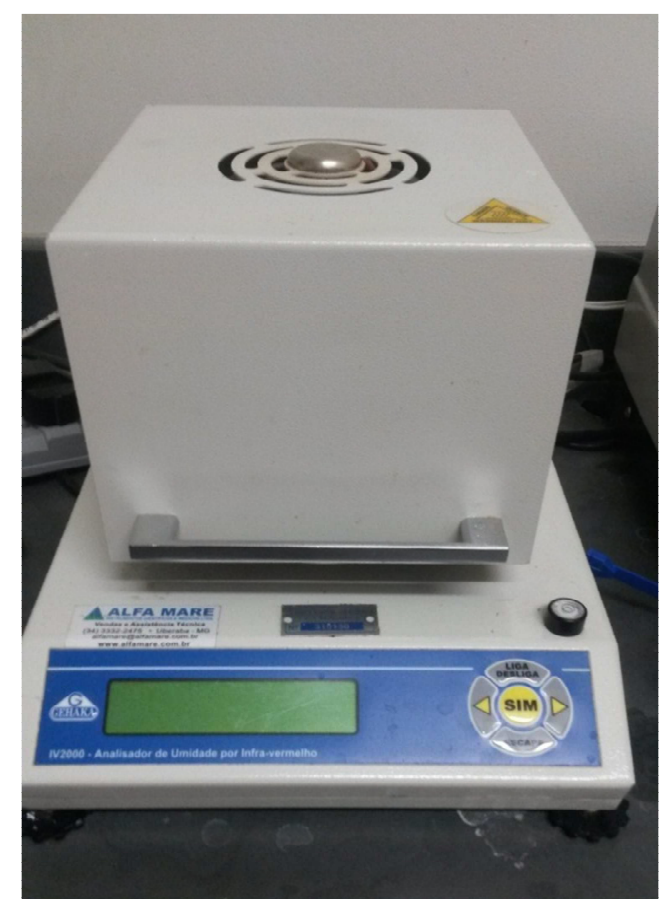

Figura 2 - Determinador de umidade.

\section{Análises físico-químicas}

Teor de acidez total titulável e ácido ascórbico: A acidez titulável total das amostras foi realizada de acordo com os métodos da Association of Official Analytical Chemists. O conteúdo de ácido ascórbico, por sua vez, foi determinado por titulometria, método que se baseia na redução do 2,6-diclorofenolindofenol pelo ácido ascórbico, e os resultados expressos em mg de ácido ascórbico em $100 \mathrm{~g}$ de amostra (AOAC, 1995).

Teor de fenólicos totais e flavonoides totais: $\mathrm{O}$ teor de fenólicos totais foi determinado pelo método espectrofotômétrico desenvolvido por Folin-Ciocalteu (Singleton e Rossi, 1965). Preparou-se uma curva padrão com ácido gálico em concentração variando de 0,2 a 2,0 $\mathrm{mg} / \mathrm{mL}$, e os resultados foram expressos em $\mathrm{g}$ equivalente de ácido gálico em $100 \mathrm{~g}$ de amostra. O solvente utilizado para a extração dos flavonoides foi o metanol. O conteúdo de flavonoides totais foi determinado pelo método colorimétrico segundo Zhishen et al., (1999). A rutina foi utilizada como padrão para a obtenção da curva de calibração. Os resultados foram expressos em $\mathrm{mg}$ equivalente de rutina em $100 \mathrm{~g}$ de amostra.

\section{Tratamento estatístico}

A Tabela 1 apresenta os modelos cinéticos utilizados neste trabalho.

Tabela 1 - Modelos de cinética de secagem.

Equação Referência

\begin{tabular}{cc}
\hline $\mathrm{MR}=\exp (-\mathrm{kt})$ & Lewis (1921) \\
$\mathrm{MR}=\mathrm{A} \exp (-\mathrm{kt})$ & Brooker et al. $(1974)$ \\
$\mathrm{MR}=\mathrm{A}(\exp (-$ & Henderson \& Henderson \\
$\mathrm{kt})+1 / 9 \exp (-9 \mathrm{kt}))$ & $(1968)$ \\
$\mathrm{MR}=\exp (-\mathrm{kt})^{\mathrm{n}}$ & Page $(1949)$ \\
$\mathrm{MR}=\exp -(\mathrm{kt})$ & Overhults et al. $(1973)$ \\
\hline
\end{tabular}

A seleção do modelo que melhor prediz a cinética de secagem foi feita considerando a significância dos parâmetros, a magnitude do coeficiente de determinação $\left(\mathrm{R}^{2}\right)$ e a distribuição dos resíduos.

Todas as análises foram realizadas em triplicata e os resultados expressos em média \pm desvio padrão. $O$ teste estatístico aplicado para o efeito da temperatura foi o Teste de Tukey $(\mathrm{p} \leq 0,05)$.

$\mathrm{O}$ adimensional de umidade (MR) foi obtido em função do tempo. A umidade de equilíbrio calculado através do método dinâmico (Arnosti et. al., 1999). O adimensional de umidade foi calculado de acordo com a Equação 1:

$$
M R=\frac{M-M_{e q}}{M_{0}-M_{e q}}
$$

\section{RESULTADOS E DISCUSSÕES}

\section{Cinética de secagem}

Na Figura 3 são apresentadas as curvas do adimensional de umidade em função do tempo, em segundos, para a secagem nas diferentes temperaturas juntamente com a predição da equação de Overhults. Observa-se que o tempo de secagem é, claramente, dependente da temperatura. Para maiores temperaturas, menor tempo necessário para atingir a umidade de equilíbrio. 


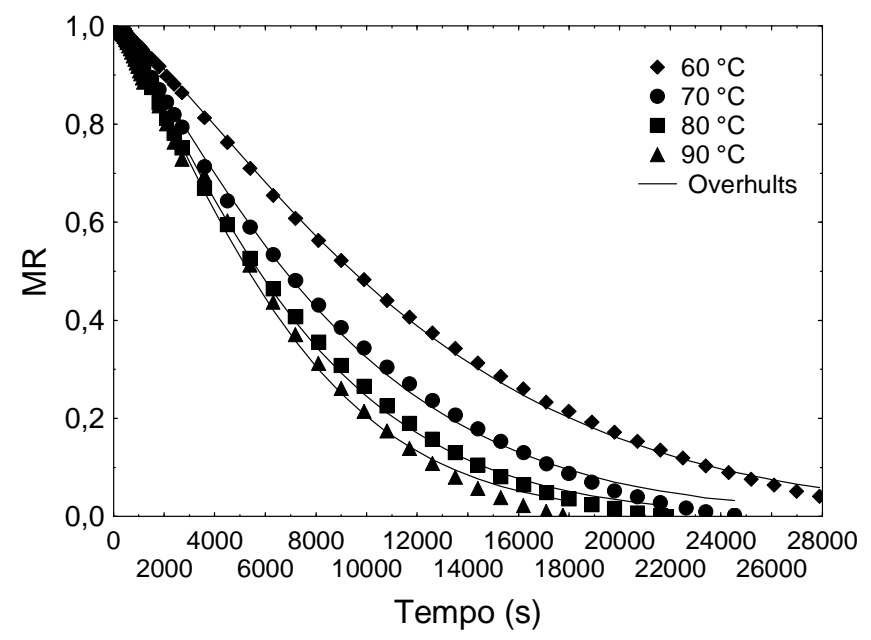

Figura 3 - Cinética de secagem da casca de mexerica para as temperaturas e o modelo de Overhults.

Estatisticamente, o modelo que melhor descreveu a cinética de secagem da casca da mexerica pokan foi o modelo de Overhults, com um coeficiente de determinação médio de 0,9993. Na Tabela 2 são apresentados os parâmetros deste modelo para cada temperatura de secagem, assim como o coeficiente de determinação.

Tabela 2 - Parâmetros para o Modelo de Overhults e o coeficiente de determinação para cada experimento.

\begin{tabular}{cccc}
\hline Experimento & $\mathbf{R}^{2}$ & ${\mathrm{k}\left(\mathrm{s}^{-1}\right)}^{\mathbf{1}}$ & $\mathbf{n}$ \\
\hline $\mathbf{6 0}$ & 0,9993 & 0,000080 & 1,301820 \\
$\mathbf{7 0}$ & 0,9991 & 0,000110 & 1,253399 \\
$\mathbf{8 0}$ & 0,9994 & 0,000131 & 1,273612 \\
$\mathbf{9 0}$ & 0,9993 & 0,000161 & 1,268088 \\
\hline
\end{tabular}

Duzzioni et. al. (2013) apresentaram este mesmo modelo como o que melhor prediz a cinética de secagem de resíduos de acerola.

\section{Análises físico-químicas}

O tempo de secagem e a temperatura de operação podem afetar a estabilidade de compostos bioativos. Neste estudo, foi avaliada a influência da temperatura nos teores de acidez total titulável, ácido ascórbico, fenólicos e flavonoides totais. Todos os resultados foram expressos em base seca.

Nas Figuras 4, 5, 6 e 7 são apresentadas comparações entre as médias de tais compostos antes (in natura) e após a secagem nas diferentes temperaturas. Letras diferentes sobre as colunas significam que as médias foram estatisticamente diferentes pelo método de Tukey $(\mathrm{p} \leq 0,05)$.

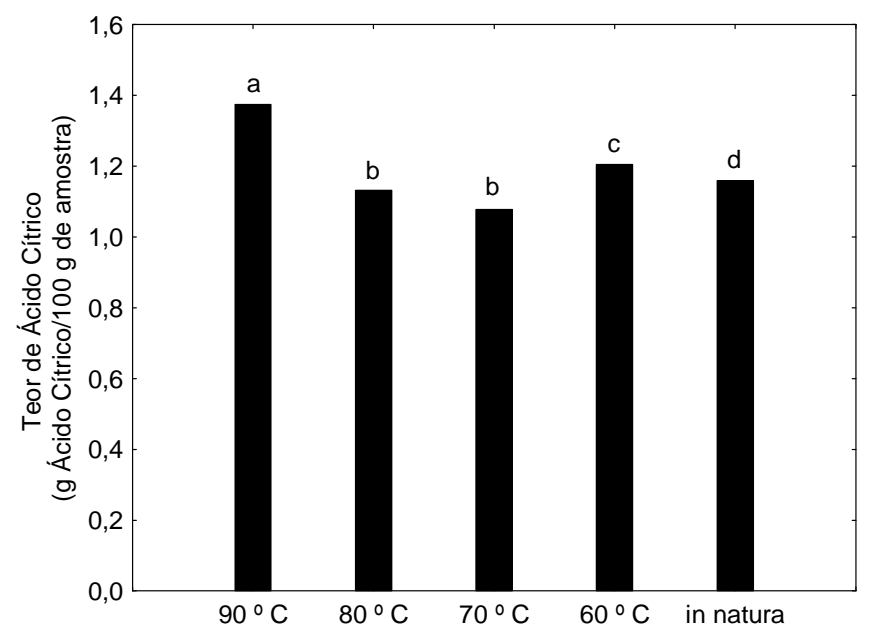

Figura 4 - Comparação do teor de acidez total titulável da casca de mexerica in natura e após a secagem.

O ácido cítrico é o ácido mais comumente adicionado em bebidas, especialmente aqueles à base de suco, para o controle do $\mathrm{pH}$, estabilização da cor; porém reivindicações foram realizadas indicando que o ácido cítrico não fornece um gosto agradável quando adicionado em bebidas (Lanton, 2004). Observa-se que nas condições de secagem em que a temperatura foi igual a 70 e $80{ }^{\circ} \mathrm{C}$ o teor de ácido cítrico (Figura 4) foi inferior ao valor obtido para o resíduo in natura

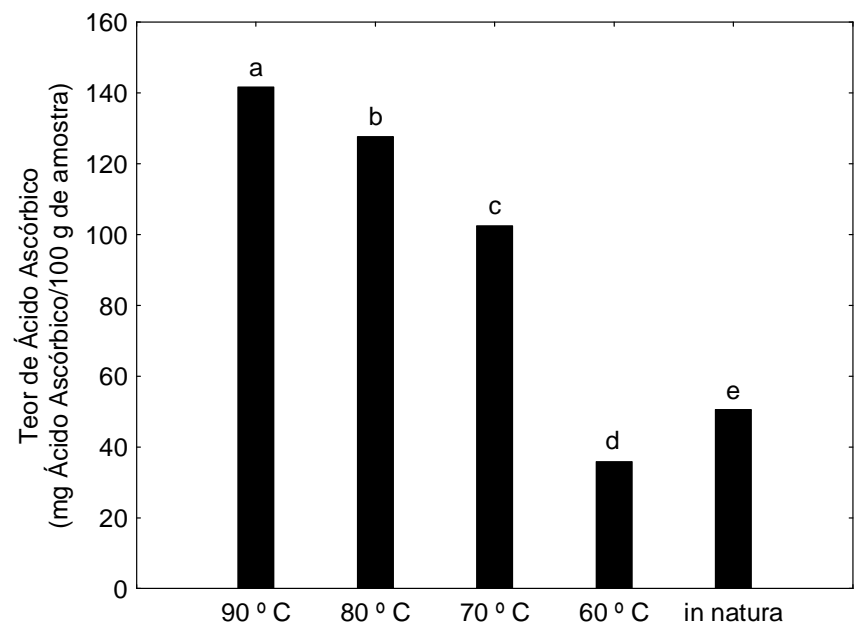

Figura 5 - Comparação do teor de ácido ascórbico da casca de mexerica in natura e após a secagem.

O teor de ácido ascórbico (Figura 5) aumentou com o aumento da temperatura de secagem para a casca da mexeria. No material 
úmido foi obtido $50,56 \pm 1,89$ (in natura) enquanto que para o material seco a $90{ }^{\circ} \mathrm{C}$ foi encontrado $141,7 \pm 5,0 \mathrm{mg}$ de ácido ascórbico/100 g de amostra. O aumento do teor de ácido ascórbico após a secagem foi explicado por Dorta et al. (2012) pela inativação de enzimas que degradam alguns compostos bioativos. O aumento no teor de vitamina $\mathrm{C}$ com o aumento da temperatura de secagem foi encontrado para outros tipos de frutas e resíduos reportados na literatura (Duzzioni et al., 2012; Ozgur et al., 2011).

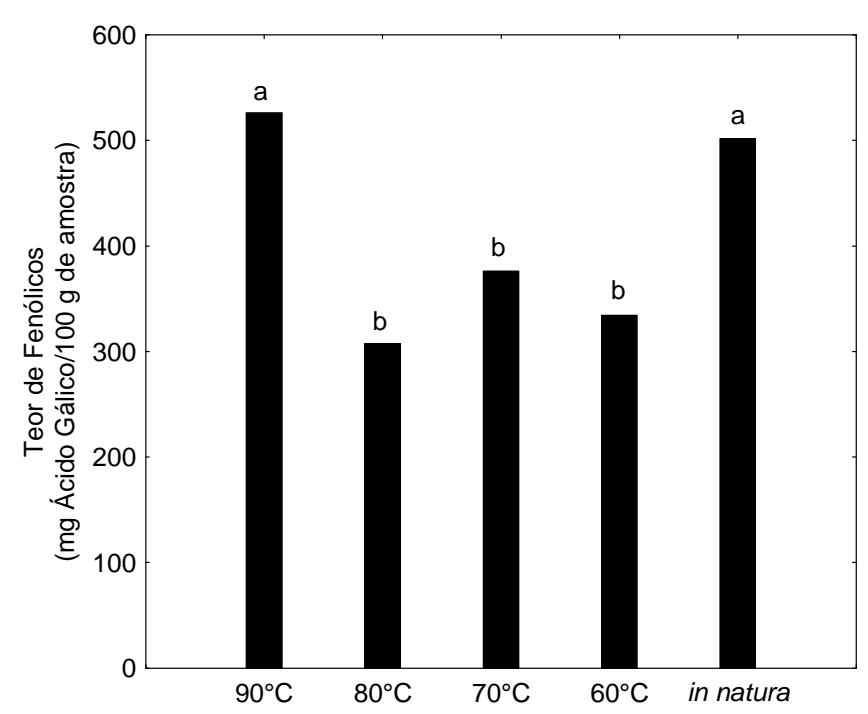

Figura 6 - Comparação do teor de fenólicos totais da casca de mexerica in natura e após a secagem.

O teor de fenólicos totais (Figura 6) obtido teve o seu máximo na temperatura de $90{ }^{\circ} \mathrm{C}(526,14 \pm 20,15 \mathrm{mg}$ de ácido gálico/100 $\mathrm{g}$ de amostra) que foi estatisticamente igual ao teor de fenólicos totais obtido para o material in natura $(501,61 \pm 32,72 \mathrm{mg}$ de ácido gálico/100 g de amostra). Logo, a desidratação não influenciou significativamente no teor de fenólicos, porém a casca de mexerica seca teria um tempo de vida útil maior após a secagem para a utilização desta em farinhas.

$\mathrm{O}$ maior teor de flavonoides totais (Figura 7) para a casca da mexerica foi após a secagem a $70{ }^{\circ} \mathrm{C} \quad(4,60 \pm 0,34 \mathrm{mg}$ de rutina/100 $\mathrm{g}$ de amostra) enquanto que na casca de mexerica in natura foi encontrado um teor igual a 3,07 $\pm 0,29 \mathrm{mg}$ de rutina/ $100 \mathrm{~g}$ de amostra. Silva et al. (2013) estudaram o resíduo de abacaxi e observaram um aumento no teor de flavonoides após a secagem.

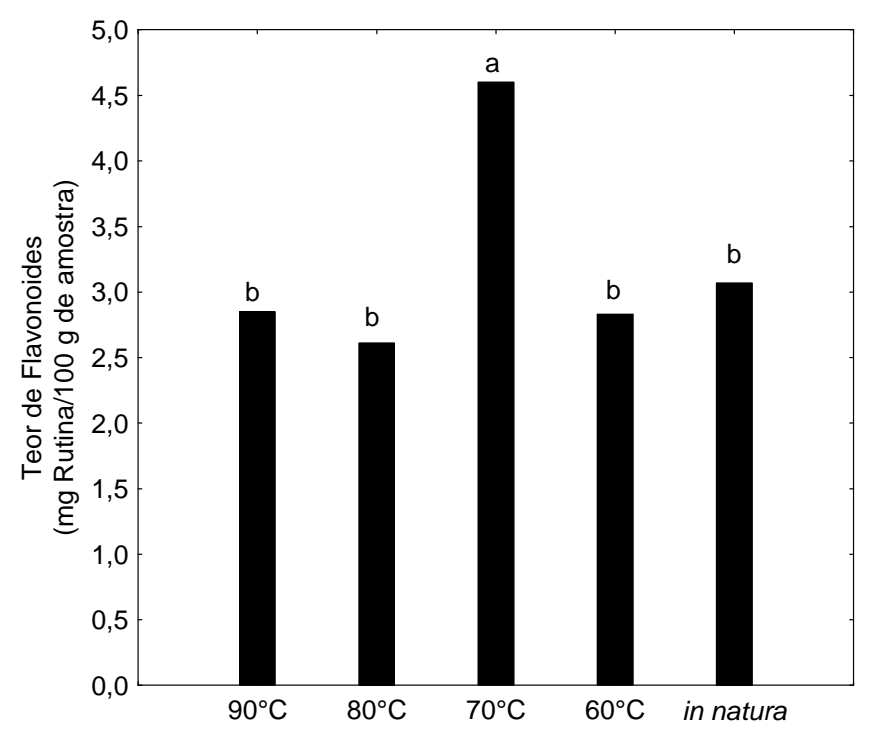

Figura 7 - Comparação do teor de flavonoides totais da casca de mexerica in natura e após a secagem.

\section{CONCLUSÕES}

O tempo de secagem é altamente dependente da temperatura de operação e esta é capaz de influenciar nos teores de compostos bioativos, sendo os flavonoides totais os menos sensíveis para a secagem da casca de mexerica. Para a temperatura de $90^{\circ} \mathrm{C}$, exceto o teor de flavonoides totais, todos os compostos apresentaram suas médias mais elevadas. Com o aumento da temperatura o teor de ácido ascórbico obtido também foi elevado.

Para o material estudado, o modelo de Overhults descreve bem a cinética de secagem nos períodos de taxa decrescente.

A secagem por infravermelho é um método eficaz na desidratação da casca e conservação da mesma, auxiliando assim no aproveitamento deste resíduo e ainda no combate à desnutrição.

\section{NOMECLATURA}

MR - adimensional de umidade;

$\mathrm{M}$ - umidade em um dado tempo;

$\mathrm{M}_{\mathrm{eq}}$ - umidade de equilíbrio;

$\mathrm{M}_{0}$ - umidade inicial. 


\section{REFERÊNCIAS}

ABUD, A. K. de S.; NARAIN, N. (2009), Incorporação da farinha de resíduo do processamento de polpa de frutas em biscoitos: uma alternativa de combate ao desperdício. Brazilian Journal of food technology, v. 12, n. 4, p. 257-265.

ANVISA: Agência Nacional de Vigilância Sanitária - Regulamento técnico sobre ingestão diária recomendada (IDR) para proteína, vitaminas e minerais, 2004. Disponível em: <http://portal.anvisa.gov.br/wps/portal/an visa/home $>$. Acesso em: 23 de julho de 2011.

AOAC INTERNATIONAL, (1995). Official methods $f$ analysis of AOAC International. 2 vols. $16^{\text {th }}$ edition. Arlington, VA, USA, Association of Analytical Communities.

ARNOSTI JR., S., FREIRE, J.T., SARTORI, D. J. M. \& BARROZO, M. A. S. (1999). Equilibrium moisture content of Brachiaria brizantha. Seed Science and Technology, 27 (1), 273-282.

BROOKER, D. B., BAKKER-ARKEMA, F. W. \& HALL, C. W. (1974). Drying Cereal Grains Avi, Westport, CT, USA.

CEASA-ES, disponível em:< http://www.ceasa.es.gov.br/?p=2533> acesso em setembro de 2013.

DUZZIONI, A. G., LENTON, V. M., SILVA, D. I. S. \& BARROZO, M. A. S. (2013). Effect of drying kinetics on main bioactive compounds and antioxidant activity of acerola (Malpighia emarginata D.C.) residue. International Journal of Food Science \& Techonology, 1-7.

HENDERSON, J. M. \& HENDERSON, S. M. (1968). A computational procedure for deep-bed drying analysis. Journal of Agricultural Engineering Research, 13, 87-95.

LANTON, B. (2004), Beyond citric acid. South African Food Review, vol. 31 n.4, p.13,.

LEWIS, W. K. (1921). The rate of drying of solid materials. Indian Chemical Engineer, 13, 427.

ODIN, A.P., (1997). Vitamins as antimutagens: advantages and some possible mechanisms of antimutagenic action. Mutation Research, Amsterdam, v.386, n.1, p.39-67.

OVERHULTS, D. G., WHITE, G. M., HAMILTON, H. E., \& ROSS, I. J. (1973). Drying soybeans with heated air, Transactions of the ASAE, 16 (1), 112113.

OZGUR, M., OZCAN, T., AKPINARBAYIZIT, A. \& YILMAZ-ERSAN, L. Functional compounds and antioxidant properties of dried green and red peppers. African Journal of Agricultural Research, 6, 5638-5644, 2011.

PAGE, G. E. (1949). Factors influencing the maximum rates of air drying shelled corn in thin-layer. Purdue University, West Lafayette, IN, USA.

RICE-EVANS, C.A.; Miller, N.J.; PAGANGA, G. (1996). Structure antioxidant activity relationship of flavonoids and phenolic acid. Free Rad. Bio. Med. , v.20, n.7, 933-956.

SANDU C.. (1986) Infrared radiative drying in food engineering: a process analysis. Biotechnology Progress 2(3): 109-119.

SILVA, D. F. P.;SIQUEIRA, D. L.; OLIVEIRA, S.P.; LINS, L. C. R.; SALOMÃO, L. C. C., (2012). Desempenho de filmes comestíveis em comparação ao filme de policloreto de vinila na qualidade pós-colheita de mexericas 'Poncã', Cienc. Rural vol.42 no.10, Santa Maria.

SILVA, D. I. S.; NOGUEIRA, G. D. R.; DUZZIONI, A. G. Changes of antioxidante constituents in pineapple (Ananas comosus) residue during process. Industrial Crops and Products SD. p. 557562, 2013.

SINGLETON, V. L.; ROSSI, J.A. Jr., (1965) Colorimetry of total phenolics with phosphomolybdic-phosphotungstic acid reagents. Amer. J. Enol. Viticult. v.16, p. 144-158.

SOUSA, C. M. M.; SILVA, H. R.; VIEIRAJR, G. M.; AYRES, M. C.; COSTA, C. L. S.; CAVALCANTE, L. C. D.; BARROS, E. D. S.; ARAÚJO, P. B. M.; BRANDÃO, M. S., CHAVES, M. H. (2007). Fenóis totais e atividade 
antioxidante de cinco plantas medicinais. Quim. Nova, v. 30, n. 2, 351-355.

SOUSA DE SÁ, P. G.; GUIMARÃES, A. L.; OLIVEIRA, A. P.; FONTANA, A. P.; DAMASCENO, P. K. F.; BRANCO, C. R. C.; BRANCO, A.; ALMEIDA, J. R. G. S. (2012), Fenóis totais, flavonoides totais e atividade antioxidante de Selaginella convoluta (Arn.) Spring (Selaginellaceae). Rev Ciênc Farm Básica Apl., 2012;33(4):561-566.

SOUZA, L. M.; CORREIA, K. C.; SANTOS, A. M. G. ; BARRETO, L. P.; NETO, E. B., (2010). Comparação de metodologias de análise de $\mathrm{pH}$ e acidez titulável. Anais JEPEX UFRPE, Recife - PE.

ZHISHEN, J., MENGCHENG, T. and JIANMING, W. (1999). The determination of flavonoid contents in mulberry and their scavenging effects on superoxide radicals. Food Chemistry 64:555-559.

\section{AGRADECIMENTOS}

Os autores agradecem ao $\mathrm{CNPq}$ e à FAPEMIG pelo apoio financeiro. 